Military Technical College Kobry El-Kobbah, Cairo, Egypt

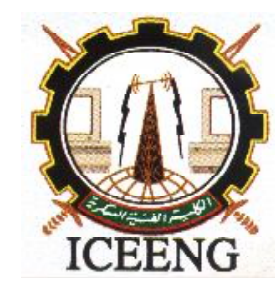

$9^{\text {th }}$ International Conference on Electrical Engineering ICEENG 2014

\title{
Military Applications of Superconductivity and Future Perspectives
}

\author{
By
}

Sajid Saleem*

\section{$\underline{\text { Abstract: }}$}

Kamerlingh Onnes of Leiden University discovered Superconductivity (SC) in 1911. Two distinguishing properties of superconducting materials are zero resistance below a certain temperature and their ability to expel the magnetic field from inside. These properties enable a size and weight reduction of 50-70\% in superconducting electrical equipment as compared to the conventional. SC has applications in many areas including military. Current military applications of superconductivity include electric power generation \& distribution, mine protection \& mine hunting, marine ship propulsion, radar and communications etc. The paper reviews the current state of military applications of superconductors and challenges (e.g. geometry, material properties, cryogenics, reliability and overall cost etc.) impeding the widespread use of superconductors in military applications. Recent developments suggesting the possible solutions to these challenges are discussed.

\section{Keywords:}

Superconductivity, marine, military, propulsion, radar, degaussing, communication

*_ ssaleem@pnec.nust.edu.pk 


\section{Introduction:}

Superconductivity is a quantum phenomenon occurring in certain materials at macro scale. Superconductors offer zero resistance to DC currents and expel the magnetic field from its bulk (Meissner effect). Three conditions for a material to superconduct and remain in superconducting state are; the material temperature has to remain below a certain temperature termed critical temperature $T_{C}$; magnetic field below the critical magnetic field called $\mathrm{H}_{\mathrm{C}}$ and the maximum current density below the critical current density $\mathrm{J}_{\mathrm{C}}$. All of these parameters are material dependent properties [1].

Kamerlingh Onnes of Leiden University first discovered superconductivity in mercury in 1911. Many other metallic elements show superconducting behavior. Collectively these elements are called low temperate superconductors (LTS). In 1986, Alex Muller and Georg Bednorz discovered superconductivity in a brittle ceramic Ba-La-Cu-O compound at $30^{\circ} \mathrm{K}$ [2]. A number of other oxide materials and compounds have been found to superconduct at even higher temperatures. A new family of arsenic based superconducting materials termed oxypnictides was discovered in 2008 [3]. These compounds are collectively called high temperature superconductors (HTS).

Superconductivity has applications in numerous fields including transportation, particle research, power generation and distribution, information technology \& computing, electronics \& telecommunications, medical diagnostic systems and marine \& military technology. Superconducting technology outshines the conventional technology by providing increased sensitivity, accuracy and performance. In large scale systems, size and weight reductions of 50-70\% can be achieved against the conventional equipment [4]. It is this reduction in size and volume, which is of more interest for military and marine systems.

\section{Current Status of Military Applications:}

Superconductors are being used by tri services; however Naval ships are the unmatched winner in the potential use of superconductors. Naval ships require energy for propulsion motors, auxiliary or main generators, degaussing, and power distribution network for ship services, directed energy weapons and radars [5]. This energy increase compared to a conventional warship requires significantly more electrical energy to power the increasing electrical loads [6]. The deployment of the electromagnetic rail gun, high power laser, high power radar, and directed energy weapons will require even more power and efficient power management to direct the energy to the required systems [7]. Superconductors are a viable solution to this increasing power demand needed for electric propulsion and directed energy weapons [8]. Many countries are 
evaluating and developing SC technology with USA being the forerunner. Specifically US Navy's SC program is one of the leading examples in this field and hence this program would be examined in detail in this paper. US Navy's superconductivity efforts gained momentum after the need for more sensitive and low-noise electronics for sensoring, detection, navigation and communication was recognized [9]. An excellent narrative of US Navy's efforts to integrate SC in fleet is [10]. US Navy is pursuing an active program labeled Naval Superconducting Integrated Power System. Planned development and acquisition of various superconducting equipment for this program is as shown in Figure 1 [11].

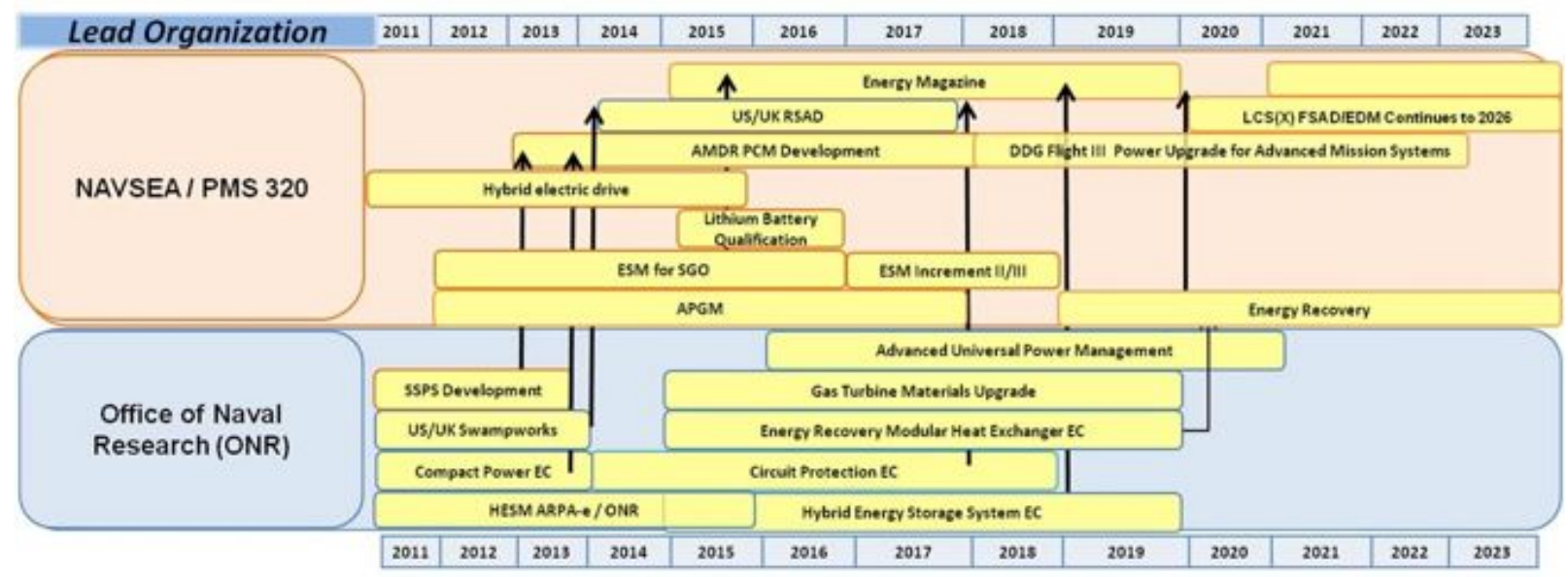

Figure 1: Integrated technology development and acquisition schedule (2013-2023) for US Navy as reported in [11]

\subsection{Power generation and Distribution:}

Electric power is the lifeline on any modern naval platform. It is estimated that the electrical power demands will increase from 0.4 MW to $20 \mathrm{MW}$ in 2020+ mainly due to sensor and weapon system demands. Power system is becoming a first order impact on overall ship design [12]. An elaborate network of power generation and distribution including generators, transforms, switchboard, voltage \& frequency convertors and Fault Current Limiters (FCL) etc. are used to produce and distribute power on a naval ship. The most important element in the network is the cabling mostly of copper, which transfers power from one place to other. Current density of HTS superconducting wire is 100 times higher $\left(30,000 \mathrm{Amps} / \mathrm{cm}^{2}\right)$ than the copper wire $\left(350 \mathrm{Amps} / \mathrm{cm}^{2}\right)$ [13], resulting in lighter and smaller systems. HTS FCLs ensure increased protection for the downstream than a conventional FCL [14]. Smaller, more efficient and oil free HTS transformers result in reduction in size and weight [15]. US Navy is currently funding dozens of cryogenic and superconducting development projects based on the promise of weight and cost reduction, higher electrical efficiency, and higher power density [5]. 


\subsection{Propulsion:}

Propulsion is the single largest energy requirement on a ship. This energy requirement is so huge that international shipping, alone, contributes 3\% of the greenhouse gas emissions [16]. Compact HTS motors having high torque and performance are an ideal candidate as propulsion motors [17]. Nearly $100 \%$ of all new commercial ships are electrically propelled [4]. For naval ships, since 2002 U.S. Navy is migrating towards an all-electric fleet. HTS motors and generators prototypes developed for the US Navy program are one-third the size and weight of their copper wound conventional counterparts and run quieter with less vibration resulting in low early detection possibility. In January 2009 world's first 36.5-megawatt (49,000 horsepower) superconducting ship propulsion motor successfully completed full-power testing. Implementation of this motor alone can reduce the ship weight by nearly 200 metric tons [12],[18].

\subsection{Degaussing / Mine Protection:}

Degaussing is the process of neutralizing the magnetic field generated by the steel hull of the ship to avoid mines [4]. Large current carrying copper wires around the ship are used for degaussing. Superconducting degaussing coils save $80 \%$ of the copper system weight resulting in smaller footprints and improved efficiency [19]. Smaller footprint of HTS degaussing system is particularly suited for submarines [20]. US Navy retrofitted USS Higgins with HTS degaussing coils in 2008. Trials of the system were conducted from June 2009 through February 2010 with over 9,000 hours of operation and 37,000 nautical miles underway at times encountering 8-10 ft seas. This trial successfully demonstrated the use of HTS for degaussing [21].

\subsection{Directed Energy Weapons:}

Sensors and Weapons are the most prominent differentiating feature between a commercial and naval platform. Traditional weapons of the naval platform e.g. guns and missiles are being replaced with novel directed energy weapons. These new weapons use high power pulses of up to $200 \mathrm{MJ}$ electrical energy [5], [7]. A very recent development (during first half of 2013) is the order placed by US Navy for the EM rail gun, which can propel projectiles or explosives at distance of 100 nautical miles travelling at mach 6 or 7 [22].

\subsection{Superconducting Electronics for Radar and Communications:}


Traditionally electronics industry has been dominated by semiconductor electronics and size reduction has been following the well-known Moore's law. Semiconductor industry has reached it size limitation due to power dissipation and thus heat. Superconductive Electronics (SE) is inherently faster at much less power dissipation than semiconductor electronics. SE provides extremely fast digital devices in a frequency range of GHz. SE is scalable and follows similar design rules as semiconductor devices. It has very low power dissipation and microprocessors and analogue-to-digital converters for commercial and military applications have been demonstrated [23]. SE with current densities from $2.5 \mathrm{kA} / \mathrm{cm}^{2}$ to $4500 \mathrm{~A} / \mathrm{cm}^{2}$ with up to nine wiring layers are available as commercial products [24]. Military uses of SE include use of Superconducting Quantum Interference Device (SQUID) for NDT and mine detection, transition-edge bolometers, radiation detection, microwave filters etc. Mixed signal rapid single flux quantum (RSFQ) integrated circuits with niobium ( $\mathrm{Nb}$ ) Josephson junctions (JJs), featuring direct digitization and digital processing of RF signals, are particularly attractive for building a variety of communication, signals intelligence (SIGINT), and electronic warfare (EW) receivers [25]. Currently SE are feasible only for those applications which require very high speed, low-power consumption, extreme sensitivity or extremely high precision [23]. SE can dramatically enhance anti-ship missile defense radars by providing the highest dynamic range digitizers for improved Signal to Noise Ratio (SNR) [4].

\section{Challenges and recent developments:}

A number of general and naval specific challenges have to be solved before the widespread use of superconductors for military applications. We have to understand that firstly, superconductivity is inherently complex as it is a multidisciplinary field encompassing as diverse areas as thermodynamics, quantum physics, cryogenics, material engineering, electrical and electronic engineering. One parameter to gauge the complexity of any field is the time gap between the actual discovery and its practical application. Superconductivity beats many other fields in terms of this measure e.g. transistor development and optical communication. Time gap between initial transistor development and first functional IC was only 11 years. Communication by light was realized in 1880 by Alexander Graham Bell, 22 years after its first concept in 1858 by J. Tyndall. However in case of superconductivity, it took 50 years after its discovery in 1911 to make the first $\mathrm{NbTi}$ magnet. Twenty-six years passed between the $\mathrm{Nb}_{3} \mathrm{Sn}$ magnet discovery and in the production of first industrial $\mathrm{Nb}_{3} \mathrm{Sn}$ magnet. HTS materials were discovered in 1987 and the market penetration has started only now i.e. 25 years later [26]. Similarly, we have yet to see any practical applications of oxypnictides since their discovery in 2008 due to their complex nature.

The second challenge has to deal with the material properties that result in high values of $\mathrm{T}_{\mathrm{C}}$ and $\mathrm{H}_{\mathrm{C}}$. Properties responsible for high values of $\mathrm{T}_{\mathrm{C}}$ include high normal state 
resistance, proximity of superconductivity to competing Anti-Ferromagnetic (AF) state, large anisotropic ratios and sensitivity of superconducting properties to local nonstoichiometry [27]. The same set of properties also lead to the lack of widespread applications of HTS. In addition, absence of any validated microscopic theory of superconductivity in HTS materials means we cannot predict new superconducting materials with higher $T_{C}$ values.

The third challenge is the geometry. The geometrical shapes of superconducting wire are limited. It is mostly available in tape format. Fabrication of SC wire (tape) requires specialist technology and process machinery due to this limitation. However, recently discovered FeAs-122 belonging to the large family of Fe pnictides, has the potential to be formed as a round wire due to its lower anisotropy value compared to other HTS materials. The disadvantage is that FeAs- 122 has lower $\mathrm{T}_{\mathrm{C}}$ values than other HTS compounds (up to $38^{\circ} \mathrm{K}$ ). Wire length of HTS is also limited due to its less manipulability than NbTi. Metallurgical difficulties in preparing high quality HTS wires and tapes in different geometries limit the use of HTS based military systems with higher $\mathrm{T}_{\mathrm{C}}$ values.

SC have to be cooled to very low temperatures for them to work. This bottleneck has seen huge improvement in recent years with micro coolers of matchbox size with milliWatt cooling power to high-reliability coolers of many Watts of cooling power for satellite applications. Reliable refrigeration adds cost and complexity to the overall equipment system [23], [28].

One very specific challenge related to Naval platforms is the use of liquid Nitrogen as the cryogenic in commercial HTS systems. Use of Nitrogen is prohibited in Naval environment due to the danger of asphyxiation [11]. For this reason Naval applications of HTS systems being developed have to be helium based [5]. However, in March 2013 CAPS researchers, under a grant from the Office of Naval Research (ONR), were able to conduct 3000 amperes of direct current through a 30 meter-long high-temperature superconductor (HTS) test cable that is cooled using pressurized helium gas [29].

\section{Conclusion:}

Military applications of SC are varied and in various stage of maturity. Some technologies such as large HTS propulsion motors and HTS degaussing systems have matured [5]. However, there are technologies such as helium cooled HTS wires which require further work. These successful programs illustrate that the SC technology works, and that it can yield great benefits. Power distribution is the next step for HTS technology development. If the engineering challenges related to SC are solved the 
resulting system could have a weight savings of $75 \%$ and a volume savings of $80 \%$. American Superconductors expect that with the new SC cable technology a $90 \%$ reduction in the total installed cable lengths for all Navy ship classes will be achieved [28]

\section{References:}

[1] J. F. Gieras, "Superconducting Electrical Machines-State of the Art," Przeglad Elektrotechniczny (Electrical Review), vol. 85, no. 12, pp. 1-19, 2009.

[2] J. G. Bednorz and K. A. Müller, "Possible high Tc superconductivity in the BaLaCuO system," Z. Physik B - Condensed Matter, vol. 64, no. 2, pp. 189-193, Jun. 1986.

[3] Yoichi Kamihara, Takumi Watanabe, A. Masahiro Hirano, Hideo Hosono, "IronBased Layered Superconductor La[O1-xFx]FeAs $(\mathrm{x}=0.05-0.12)$ with $\mathrm{Tc}=26$ K,” J. Am. Chem. Soc., vol. 130, no. 11, pp. 3296-3297, 2008.

[4] A. Lauder, "Military Benefits of Superconductor Based Equipment," The Coalition for the Commercial Application of Superconductors, 27-Mar-2013. [Online]. Available: http://www.ccasweb.org/pdf/MilitaryBenefitsSuperconductorBasedEquipment.pdf. [Accessed: 17-Dec-2013].

[5] J. Miller, D. Santosusso, M. Uva, K. Woods, and B. Fitzpatrick, "Naval Superconducting Integrated Power System (SIPS)," presented at the Intelligent Ships Symposium, 2013.

[6] N. Doerry, "Next generation integrated power systems (NGIPS) for the future fleet," presented at the IEEE Electric Ship Technologies Symposium, 2009.

[7] T. Wolfe, P. Riedy, J. Drake, F. MacDougall, and J. Bernardes, "Preliminary Design of a 200 MJ Pulsed Power System for a Naval Railgun Proof of Concept Facility," presented at the 2005 IEEE Pulsed Power Conference, pp. 70-74.

[8] H. Zhao, J. Jin, and X. Lu, "Advantage of HTS DC power transmission," presented at the 2009 International Conference on Applied Superconductivity and Electromagnetic Devices (ASEMD), pp. 403-406.

[9] R. Ross, C. Meijer, and R. Hunik, "Maritime Superconductivity Perspectives," IEEE Trans. Appl. Supercond., vol. 23, no. 3, pp. 3601405-3601405, 2013.

[10] D. U. Gubser, "US Navy's Superconductivity Programs Scientific Curiosity to Fleet Utility," Applied Superconductivity, IEEE Transactions on, vol. 21, no. 3, pp. 931-935, 2011.

[11] T. J. McCoy, M. Smoot, J. Kuseian, H. Marshall, and M. Collins, "Naval Power Systems Technology Development Roadmap PMS 320," presented at the American Society of Naval Engineers (ASNE), 2013, pp. 1-95.

[12] D. T. J. McCoy and H. Marshall, "Military Smart Grids \& Microgrids," 
presented at the The Gov/Mil Smart Grids and Microgrids Symposium, 2013, pp. $1-19$.

[13] Q. Li, M. Suenaga, Z. Ye, S. R. Foltyn, and H. Wang, "Crossover of thickness dependence of critical current density J c $(\mathrm{T}, \mathrm{H})$ in $\mathrm{YBa} 2 \mathrm{Cu} 3 \mathrm{O} 7-\delta$ thick films," Applied physics letters, vol. 84, no. 18, pp. 3528-3530, 2004.

[14] P. Malkin, "Design and Performance Considerations for a Superconducting Electric Power System to power future Aircraft," presented at the 49th AIAA/ASME/SAE/ASEE Joint Propulsion Conference, Reston, Virginia, 2013.

[15] CCAS, "Infrastructure Benefits," The Coalition for the Commercial Application of Superconductors, 27-Feb-2013. [Online]. Available: http://www.ccasweb.org/pdf/InfrastructureBenefits.pdf. [Accessed: 17-Dec-2013].

[16] S. Nishijima, S. Eckroad, A. Marian, K. Choi, W. S. Kim, M. Terai, Z. Deng, J. Zheng, J. Wang, K. Umemoto, J. Du, P. Febvre, S. Keenan, O. Mukhanov, L. D. Cooley, C. P. Foley, W. V. Hassenzahl, and M. Izumi, "Superconductivity and the environment: a Roadmap," Supercond. Sci. Technol., vol. 26, no. 11, p. 113001, Sep. 2013.

[17] B. Fitzpatrick, "Military Applications," 29-Jun-2010. [Online]. Available: http://www.htspeerreview.com/pdfs/presentations/day\%201/plenary/Fitzpatr.pdf. [Accessed: 17-Dec-2013].

[18] “365-megawatt-superconducting-motor.html," nextbigfuture.com. [Online]. Available: http://nextbigfuture.com/2009/01/365-megawatt-superconductingmotor.html. [Accessed: 17-Dec-2013].

[19] J. T. Kephart, B. K. Fitzpatrick, P. Ferrara, M. Pyryt, J. Miller, and C. Nadig, "Flow Resistance Experiments in HTS Cable Form," Applied Superconductivity, IEEE Transactions on, vol. 23, no. 3, pp. 5401304-5401304, 2013.

[20] R. Ross, C. G. Meijer, and R. J. van de Mheen, "Degaussing by Normal And Superconductive Windings," presented at the 11th INEC, Edinburgh,U.K, vol. 11.

[21] J. T. Kephart, B. K. Fitzpatrick, P. Ferrara, M. Pyryt, J. Pienkos, and E. M. Golda, "High temperature superconducting degaussing from feasibility study to fleet adoption," Applied Superconductivity, IEEE Transactions on, vol. 21, no. 3, pp. 2229-2232, 2011.

[22] "navy-awards-em-railgun-contract," defensetech.org. [Online]. Available: http://defensetech.org/2013/07/03/navy-awards-em-railgun-contract/. [Accessed: 17-Dec-2013].

[23] S. Anders, M. G. Blamire, F. I. Buchholz, D. G. Crété, R. Cristiano, P. Febvre, L. Fritzsch, A. Herr, E. Il'ichev, and J. Kohlmann, "European roadmap on superconductive electronics-status and perspectives," Physica C:

Superconductivity and its applications, vol. 470, no. 23, pp. 2079-2126, 2010.

[24] J. Kunert, O. Brandel, and S. Linzen, "Recent Developments in Superconductor 
Digital Electronics Technology at FLUXONICS Foundry," IEEE Trans. Appl. Supercond., vol. 23, no. 5, p. 1101707, 2013.

[25] D. Gupta, D. E. Kirichenko, V. V. Dotsenko, R. Miller, S. Sarwana, A. Talalaevskii, J. Delmas, R. J. Webber, S. Govorkov, and A. F. Kirichenko, "Modular, multi-function digital-RF receiver systems," Applied Superconductivity, IEEE Transactions on, vol. 21, no. 3, pp. 883-890, 2011.

[26] R. Flükiger, "Overview of Superconductivity and Challenges in Applications," Rev. Accl. Sci. Tech., vol. 5, pp. 1-23, Jan. 2012.

[27] A. Gurevich, "To use or not to use cool superconductors?," Nat Mater, vol. 10, no. 4, pp. 255-259, 2011.

[28] A. P. Malozemoff, "Does the electric power grid need a room temperature superconductor?," Physica C: Superconductivity and its applications, vol. 494, no. C, pp. 1-4, Nov. 2013.

[29] "Florida State Center for Advanced Power Systems researchers achieve major breakthrough / More FSU News - Florida State 24/7," news.fsu.edu. [Online]. Available: http://news.fsu.edu/More-FSU-News/Florida-State-Center-forAdvanced-Power-Systems-researchers-achieve-major-breakthrough. [Accessed: 17-Dec-2013]. 